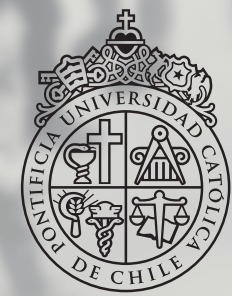

PONTIFICIA

UNIVERSIDAD

CATÓLICA

DE CHILE
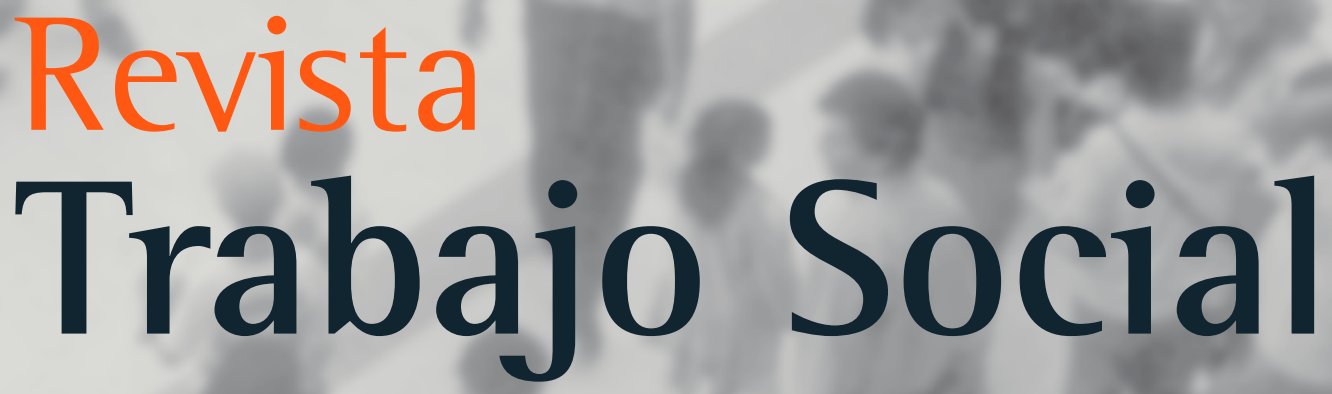

La relación de ayuda en Trabajo Social.

Propuestas para un desarrollo de calidad

Mercedes GonzÁlez Vélez,

Pilar Blanco Miguel,

Cinta Martis Sánchez,

Mabuela Fernández Borrego,

Pablo Álvarez Pérez

Prácticas de asistencialidad de Trabajo Social

en la política social de

salud chilena

Patricia Castañeda Meneses,

Ana María Salamé Coulon
¿Qué se enseña y cómo se enseña investigación en las escuelas de Trabajo Social?:

Aproximaciones a la formación profesional de cuatro universidades de la Región Metropolitana

Pamela Andrea Henríquez Ensemeyer

\section{Prisión, género} masculino y Trabajo Social:

Una autorreflexión en torno a dimensiones a considerar

Victor I. GARCía,

Eduardo Zavala-Mendoza

\section{Análisis psicométrico} preliminar

de un instrumento para evaluar indicadores proteccionales en situaciones de maltrato infantil grave (I-PROT)

Valeria Arredondo, Carolina Saavedra, Cristóbal Guerra 



\title{
Prisión, género masculino y Trabajo Social: Una autorreflexión en torno a dimensiones a considerar
}

\section{Prison, male gender and Social Work: A reflection on dimensions to be considered}

\author{
Victor I. García, Eduardo Zavala-Mendoza \\ Email: vicgarciatoro@yahoo.es
}

\begin{abstract}
Resumen
Nos proponemos analizar críticamente la necesidad de autorreflexionar en torno a la violencia y su vínculo con tres dimensiones que inciden sobre la prisión como fenómeno social y al Trabajo Social como profesión. Es decir, exploramos la relación de la violencia con el paradigma, discurso y masculinidades. Esto implicaría la necesidad de considerar nuevos paradigmas que sean cónsonos con el ofrecimiento de tratamiento a la creciente población de hombres internados-privados de libertad en instituciones penales. La perspectiva tradicional encara la violencia como un fenómeno naturalmente masculino por la propia naturaleza de las masculinidades. De esta forma, se establece un vínculo entre violencia y género masculino que hace necesario repensarlo, reenfocarlo. Es una paradoja o bien una contradicción que, en sociedades dominadas básicamente por hombres, estos no se percaten del impacto y los efectos adversos de las políticas públicas negativas de encierro. Esto redunda sobre la violación de derechos humanos y civiles al amparo de las leyes, exclusión y opresión, versus el tratamiento que propone la eventual reinserción en sociedad.

Conceptos claves: Género masculino, paradigma, discurso de la masculinidad hegemónica, violencia, prisión, políticas públicas, derechos humanos, opresión y tratamiento.

Abstract

We propose to analyze critically the need to reflect on three dimensions that affect prison as a social phenomenon and social work as a profession. I refer to the relationship between violence and the paradigm and the discourse of masculinities. This would imply the need to consider new paradigms that are consistent with the offer of treatment to the growing population of interned men-deprived of their liberty in Criminal Institutions. The traditional perspective views violence as a naturally masculine phenomenon by the very nature of masculinities. In this way, a link between violence and masculine gender is established that makes it necessary to re-think it, to re-focus it. It is a paradox or rather a contradiction that in societies dominated by men, they do not realize the impact and adverse effects of negative public policies of confinement on the violation of human and civil rights under the laws and exclusion and oppression, Versus the treatment proposed by the eventual reintegration into society.
\end{abstract}

Key words: Masculine gender, paradigm, hegemonic masculinity discourse, violence, prison, public policies, human rights, oppression, treatment.

\section{Introducción}

Resulta evidente la creciente necesidad de dar paso a iniciativas que orienten y profundicen en las diversas manifestaciones de la violencia relacionadas a las dimensiones paradigmáticas, discursivas y de masculinidades. Esta preocupación parece coincidir con investigaciones de género desarrolladas desde diversos espacios de los feminismos y masculinidades (Quiroz \& Pineda, 2009; Von Gaudecker, Van Soest \& Wengströn, 2011; Martinuzzi, 2013). Es decir, se consolida la necesidad de generar un preámbulo, por así decirlo, que permita poder conocernos mejor y adelantar la agenda hacia un 
diálogo que promoviese a su vez la igualdad y la equidad entre los géneros, tanto femenino como masculino. Respecto a las masculinidades, ha habido una tendencia marcada en nuestras sociedades de vincular la violencia al género masculino, como si fuese algo que le caracteriza por naturaleza, que le es propio; no así con relación a las mujeres, a quienes de modo general se les ve como víctimas o receptoras de esa violencia que tiende a ser mayormente física, hiriente y humillante. Los estudios de violencia en la relación de pareja así parecen evidenciarlo (Colon, Burgos \& García, 2006).

En tal sentido, la noción de violencia que predomina es, de modo general, la que se evidencia, palpa y que cotidianamente es reconocida como la violencia física. Esta, según Van Soest (1997), se encuentra en el ápice de la pirámide, considerándole como un fenómeno global estrechamente vinculado a la pobreza, estructura y vulneración de derechos humanos y civiles. Sin embargo, consideramos que al hablar de este tema se debe pluralizarle a partir de sus diversos significados, para que así se pueda alcanzar y aquilatar su diversidad y el efecto de sus acciones, no solo en los individuos sino también en la sociedad. Esto quiere decir que sus denominaciones pueden ir desde violencia simbólica, siendo aquella que, sutilmente o no, nos obliga a aceptar valores, verdades, preferencias, opciones, maneras de entender, organizar y hacer (Rivera, 2009). O bien, violencia cultural, misma que proviene de las profundas raíces de nuestra cultura y de las cuales no podemos liberarnos tan fácilmente; por ende, puede pasar invisible o imperceptible.

Entonces, lo anterior argumenta una necesidad de percibir la violencia más allá de la idea y efecto únicamente en lo físico o lo que parece palpable. Con ello, será posible concebirle en sus diversas manifestaciones simbólicas y culturales, por mencionar algunas. Es decir, se visibilizará la violencia insertada en las políticas públicas, códigos comunicativos, religión, academia, deportes y literatura. De igual forma, en todos los campos del bienestar social, acción social y cultural, nutriendo las cifras de la criminalidad - una de las dimensiones de la violencia-y, alimentando así invariablemente la noción de que los hombres son violentos por naturaleza. De tal forma, para abordar los elementos anteriormente descritos, es necesario el estudio y autorreflexión crítica de la violencia, pero en vínculo de la dimensión paradigmática, discursiva y de masculinidades.
Tal y como veremos más adelante, estos aspectos configuran un fenómeno en la prisión, impactando directamente el ejercicio profesional del Trabajo Social. Para esto, abordaremos temáticas aglutinadas en cuatro secciones. Primero, brindaremos un acercamiento epistemológico y teórico de las categorías analíticas centrales: paradigma, discurso, violencia, prisión y género masculino. En segundo lugar, abordaremos la relación de la dimensión paradigmática, discursiva y de masculinidades vinculados a diversos tipos y procesos de la violencia. De esta forma, analizaremos su impacto en el contexto institucional, dando paso a la problematización del paradigma de tratamiento ${ }^{1}$ en las prisiones. Tercero, se presentarán algunas consideraciones fundamentales que, frente al fenómeno de la prisión, el profesional del Trabajo Social debe tener presente. Y, en cuarto lugar, se presentarán ciertas conclusiones y autorreflexiones finales.

\section{Acercamiento epistemológico y teórico}

\section{Paradigma y discurso de las masculinidades}

Para iniciar el abordaje epistemológico y teórico, es necesario revisar diversas definiciones de algunas categorías centrales que guiarán la discusión a lo largo del presente trabajo. En tal sentido, el paradigma, según Kuhn (2004), es la dimensión que configura conceptualmente los principios, normas, reglas, metodologías y teorías, que determinarán la forma epocal de hacer ciencia y, por lo tanto, de pensar y hacer. Es decir, el paradigma discurrirá en la producción intelectual y en la forma como vemos e interpretamos. En otras palabras, y relacionando los temas que acá interesa, el paradigma define los niveles discursivos en la sociedad.

De tal manera, por discursos entenderemos el conjunto de directrices, códigos, entendidos, expectativas, guiones, papeles esperados, requisitos, distintivos y características que le constituyen. A su vez, el discurso trae consigo dos fundamentos que actúan como referentes y que son entronizados mediante la validación por las estructuras con mayor ventaja en las relaciones de poder: las verdades -lo que es- y sus legitimidades -lo que se espera-. En este sentido, nos acercamos a una referencia que vincula a las verdades y a los paradigmas (Foucault, 2010).

Lo anterior convierte a los discursos en dispositivos predominantes en la sociedad, entre ellos el de

1. Sabemos que, dentro del contexto del Trabajo Social, a las acciones profesionales le denominamos como intervenciones. No obstante, consideramos que en el ámbito penitenciario la noción de tratamiento nos refiere al conjunto de procesos donde se da el accionar profesional al interior de los equipos multidisciplinarios criminológicos junto a la población, estructura institucional y la comunidad. 
la masculinidad hegemónica a partir de la significación patriarcal. Esto nos dirá Forastelli, "refiere a los procesos materiales y simbólicos de opresión y discriminación en la que está involucrada la misma estructura de los géneros y, por lo tanto, expone a un sujeto que es, al mismo tiempo, colectivo y heterogéneo" (2007, p. 53). Con ello, sus guías, definiciones y requerimientos promueven, en gran medida, el que los propios hombres se conviertan en prisioneros de la violencia y que la sociedad alimenta y valida a través de procesos como la socialización, entre otros (García, 2012a). Así, tal y como se ilustra en la Figura 1, estos hombres son a la vez víctimas, actores y sujetos de los paradigmas y discursos que rigen nuestra sociedad.

En tal sentido, emerge una innegable interrelación

FIGURA No1

RELACIÓN ENTRE PARADIGMAS, DISCURSOS Y MASCULINIDADES

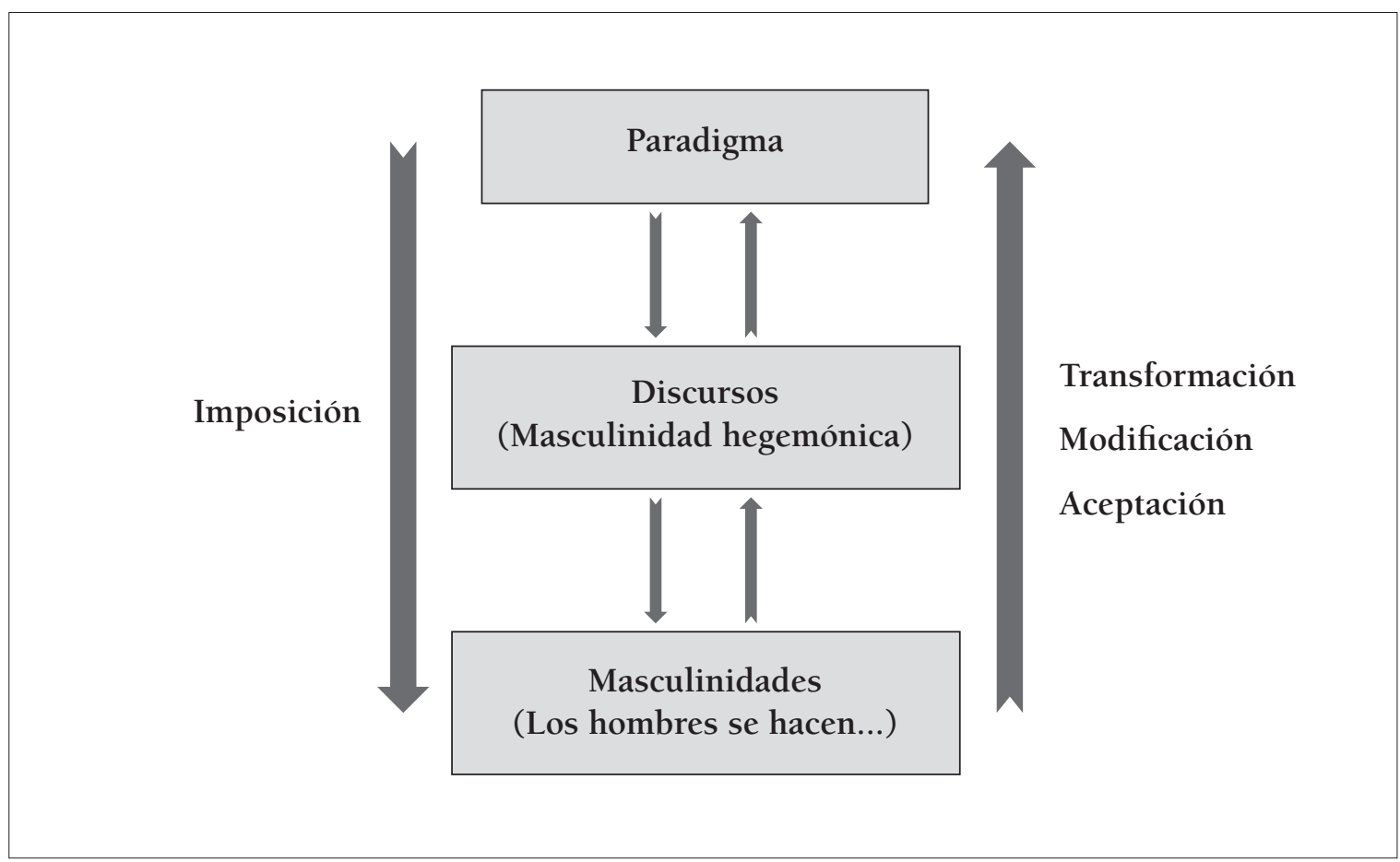

Fuente: Elaboración propia (2017). Hacemos la salvedad de que, de ninguna forma, se podrán percibir las figuras que acá se presentan como asuntos finales, pues a relacionarse a fenómenos sociales, están sujetas a cambios y modificaciones que las hagan pertinentes a los contextos con los cuales podamos vincular.

entre los paradigmas, discursos y acciones. De esto emana a diferentes niveles, sea por imposición, opresión y aplicación, la base desde donde como profesionales del Trabajo Social debemos considerar críticamente para enmarcar nuestras ejecutorias. Ignorarlos, incorporarlos y aceptarlos acríticamente incide no solo en nuestro quehacer profesional sino también en acciones de formas definidas sobre los actores, instituciones y poblaciones con las cuales nos relacionamos. Quizá podría ayudar el preguntarnos, ien qué medida podemos promover la transformación? Esto aplicaría por un lado la nuestra y, por otro, la de nuestros colegas y gremio profesional en aras de una más efectiva y eficiente ejecutoria profesional.
Vinculado a lo recién expresado y haciendo referencia a la situación actual de control y encierro, el artículo titulado Masculinidad y Violencia de García, Ramírez y Solano (2007) ofrece un acercamiento a algunos de los problemas de los hombres privados de libertad en las prisiones. A saber:

Tal vez sea momento de preguntarnos si es eso lo que esta población necesita y trabajar hacia el desarrollo de nuevos paradigmas de educación, de masculinidad, de prevención de la violencia y de sistemas de control social, de sistemas de corrección y de rehabilitación, enfocados en una perspectiva de género masculino. (pp. 170-171)

Continuando en esta misma reflexión, los mismos autores argumentan que: "debemos ponderar 
seriamente si estamos lidiando con esquemas de opresión sobre estas poblaciones, específicamente sobre estos hombres, que son a su vez producto de la violencia que corre a lo largo y a lo ancho de nuestra sociedad" (p. 171).

Las referencias a este trabajo traen consigo claramente la preocupación con el impacto de los paradigmas y discursos que hacen parte de nuestro diario vivir. Bajo esta consideración, notaremos que guían conscientemente o no las acciones de los miembros de la sociedad, tanto hombres como mujeres, por ende, a los profesionales de Trabajo Social. Dicho sea de paso, esto será visibilizado con mayor notoriedad en los hombres mediante las diversas manifestaciones de la masculinidad -sobresaliendo una variante hegemónica-, especialmente en lo relativo a la asociación con la violencia en sus variados y crecientes espacios de acción.

Así, el discurso de la masculinidad hegemónica construye y asigna una serie de criterios que distinguen al hombre masculino como aquel heterosexual, lo que se establece a nivel discursivo como la verdad. Es decir, no evidencia sentimientos -ya que se significa como señal de debilidad-, es proveedor principal del hogar, tiene control sobre los miembros y utiliza la fuerza y violencia cuando estime necesario, entre otros. De igual forma, este discurso y sus variantes según las diferentes sociedades mantiene una serie de requisitos que, a pesar de los cambios sociales, parecen e insisten en prevalecer. Esto significa que se legitima discursivamente mediante la expectativa de que el hombre es de la calle -es decir, de la esfera pública- y a la mujer del hogar -o sea, de la esfera privada-, siendo que, discursivamente, el hombre masculino es por orden la antítesis de lo femenino.

\section{Violencia}

Como se ha mencionado anteriormente, tras el discurso se esconde toda una instrumentación que genera violencia, donde diversas estructuras de la sociedad se han ocupado de manejar a su conveniencia. Es decir, la violencia se utiliza en formas sofisticadas y en diversos niveles. O sea, se puede justificar la violación intencionada de los derechos humanos y civiles, la violencia policial e inclusive el femicidio, el asesinato de la "adúltera" y el castigo "merecido" de la mujer que no se subordina a los deseos del hombre masculino. Incluso, esto es en ocasiones desmedida contra otros hombres. Este discurso y los guiones que trae consigo llevan al hombre desde el proceso de socialización en el hogar y en la escuela con los pares y en el campo de trabajo, a involucrarse en diversas manifestaciones de la violencia, validando así su masculinidad, cualquiera que esta sea. Esto se detalla en la Figura 2.

Entonces, la influencia de los paradigmas y el discurso sobre las masculinidades privadas de libertad conlleva una gran contradicción. Es decir, evidencia sus efectos en las incoherencias que acarrea consigo toda intención de acción profesional sobre individuos que, por razones legales, mayormente, advienen a instituciones penales de cualquier tipo. Desde la perspectiva de Trabajo Social, la vulneración de los derechos humanos, la opresión y violencia en las formas de acción institucional cuestionan los principios básicos de la ética profesional bajo el manto de las exigencias legales y administrativas a nivel institucional. Con todo pareciera que nuestra profesión, ajena a esta realidad, actúa como si pudiese ser inmune a todo el peso que implica sobre la sociedad, las instituciones, la familia y los individuos.

En tal sentido, los procesos al interior de las posibles y diversas instancias de acción cuestionan nuestras propias bases profesionales y nos ponen frente a desafíos que requerirían un repensar. Es decir, esto resulta necesario ya que nos situamos como parte de un teatro plagado de incoherencias y contradicciones. Este llamado toma fuerza a partir de las enseñanzas de Jane Adams, quien fuese pionera de la profesión, en el hecho de que no se deben aceptar ciegamente las leyes. Por el contario, si no hay cuestionamiento a las mismas, el Trabajo Social tiene un serio problema como profesión (García, 1982).

En tanto, a nivel de la sociedad definimos el crimen -en el discurso-, enseñamos a actuar en el crimen -estableciendo el guion-, juzgamos, encerramos y rehabilitamos -mediante el paradigma-. En ocasiones, castigamos absurdamente al criminal para luego intentar reintegrarlo -en vano en gran medida- a la sociedad de forma "productiva". Con ello, paradójicamente hemos creado toda una infra- y superestructura para promover y a su vez lidiar con este tipo de violencia, para tranquilizar a la sociedad y ofrecerle seguridad y controles -bajo un manto protector de legalidad- a través del Estado y sus estructuras con ventaja en las relaciones de poder.

\section{Prisión y género masculino}

Se suma a lo antes expuesto el efecto adverso de la llamada "feminización" de las masculinidades, un asunto sumamente serio que necesitaría dedicársele otro trabajo. Nos referimos a que el encierro trae consigo la negación de la masculinidad hegemónica. Es decir, esto implica la pérdida del merodeo 


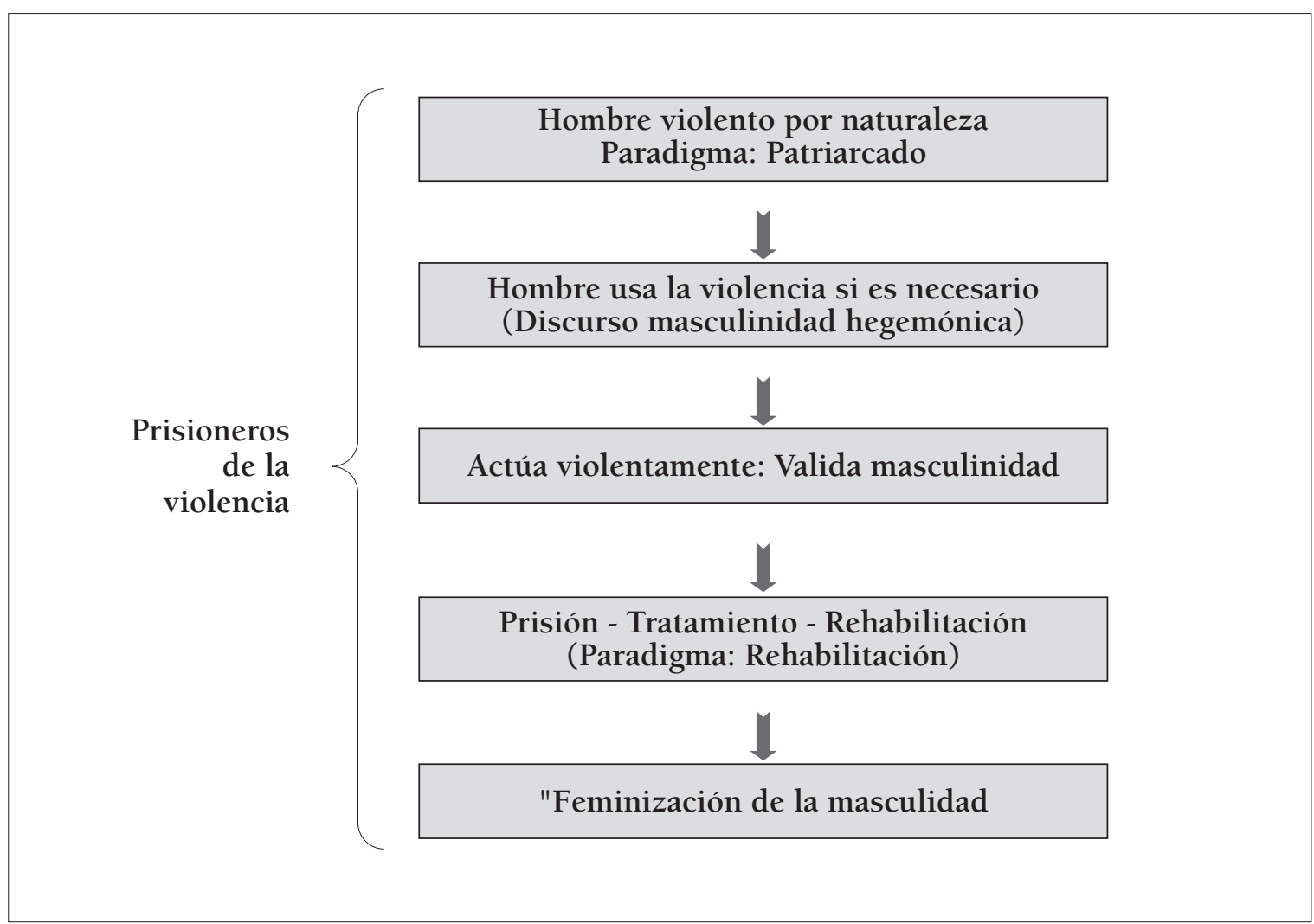

Fuente: Elaboración propia (2017).

en libertad en la calle y en lo público; la oportunidad de ejercer su heterosexualidad; la oportunidad para sustentar su familia; la oportunidad de ejercer control sobre otros y el constante acecho a su masculinidad, entre otras; esto, dado el mundo homosocial y homoerótico donde se ubica mientras esté privado de libertad bajo el amparo de la estructura pública.

Finalmente, podríamos decir que los discursos se alimentan de paradigmas, es decir, verdades no cuestionadas y en ocasiones ni actualizadas con el rigor necesario. Esto, representa una razón por la cual no nos preocupamos sobre los mismos, y menos sobre su pertinencia y efectividad sobre los hombres, sus conductas, sus acciones y su porvenir, con mucha frecuencia sujetos a los requerimientos de la propia sociedad donde viven. Este cuestionamiento no es autógeno, visto que la historia nos ha demostrado cómo algunos paradigmas se sustentan contra las realidades cotidianas por falta de voluntad política de los ciudadanos a niveles individuales, grupales y sociales en problematizarlos y transformarlos.

\section{Dimensiones de la violencia:}

Violencia y masculinidades: su relación con paradigmas y discursos

Desde la perspectiva de los estudios de género, la manifestación de la violencia y, en este caso particular, la adscrita al género masculino, se considera como la demostración más dramática del potencial destructivo de la propia masculinidad (Kaufman, 2003). Es decir, tal como se presenta en la Figura 3, la violencia se encuentra institucionalizada en diversos niveles de la vida económica, política, social y cultural.

Las fuentes de la violencia en sus diferentes manifestaciones son vastas y abarcan hasta llegar a las dimensiones de la cultura (Van Soest, 1997; Arendt, 2006). Resultan de las interrelaciones al interior de sí misma y se operativizan a través de las múltiples instituciones y organizaciones de la sociedad, las cuales se ubican al amparo del Estado y de su poder ejercido. Las estructuras y grupos con ventajas en las relaciones de poder económico, político y social, en sincronía y secuencia de acciones lógicas, definen, incorporan, controlan y, por así decirlo, 


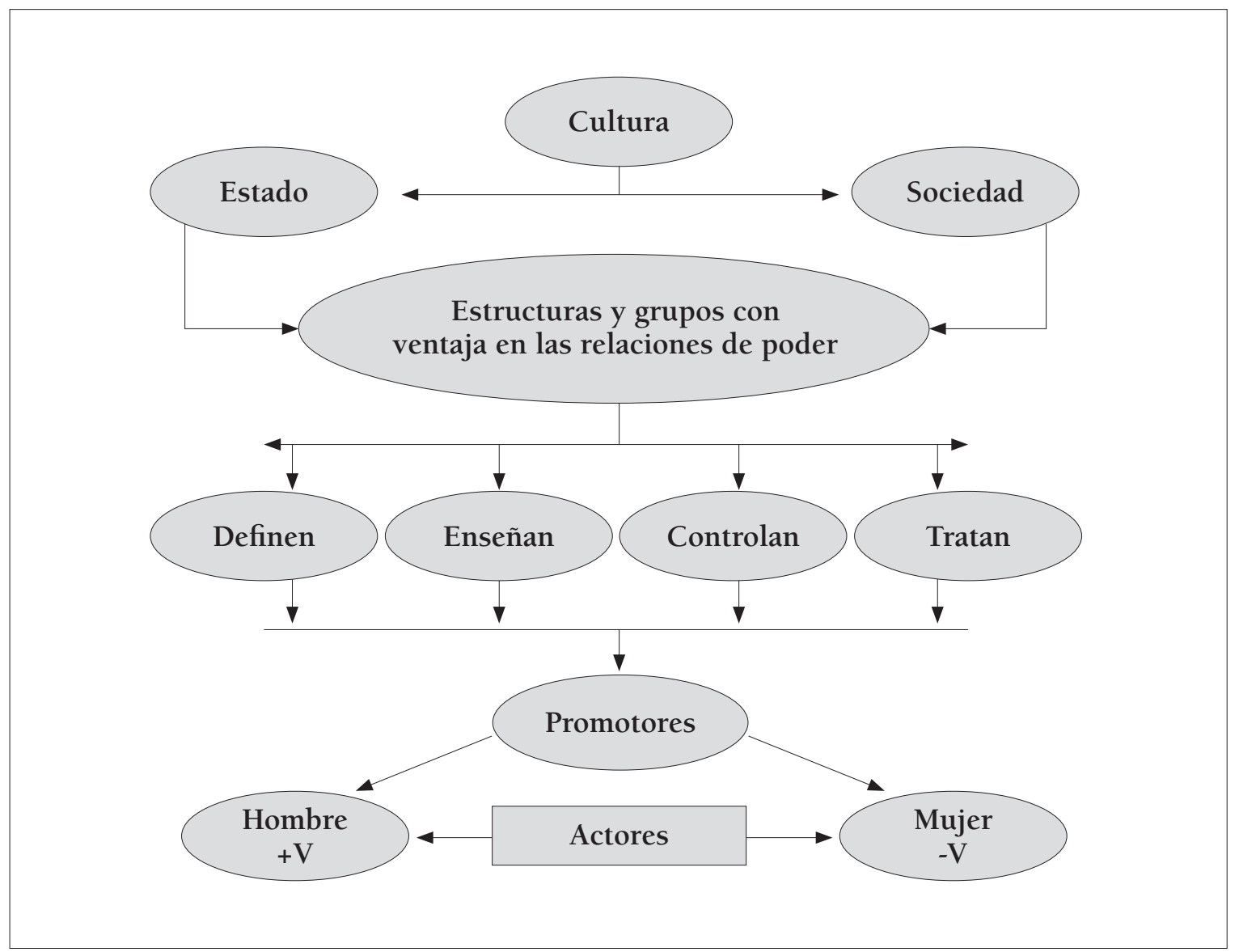

Fuente: Elaboración propia (2017).

tratan las violencias. Esto, se entiende, relaciona y modela según la referencia del género masculino, principalmente.

En tal sentido, lo anterior nos posiciona como "actores" y "actrices" profesionales de una violencia densa, difusa y en ocasiones letal que no se consigue detener. Al interior del Trabajo Social toda esta discusión, ocasionalmente, nos atrapa a partir de un carácter personal y no tanto desde la perspectiva profesional. Esto nos lleva a ser cómplices de los procesos que emanan de tal situación, con lo que se apalabra, mimetiza a nuestros participantes -o clientela en algunos espacios-, implementando discursos y llevándolo a cabo en nuestras intervenciones profesionales. Es decir, en ocasiones partimos de la violencia diferenciada: para con los hombres, como lo esperado, lo inevitable; para lo femenino, lo inesperado e inusitado y, en más de una ocasión, comprensible por su "propia constitución" al interior de los discursos predominantes.
Tanto es así, que en el proceso de socialización los hombres demuestran la ritualización de la violencia internalizada a través de los desapegos existentes como cuando recurren, por ejemplo, a la pelea física como forma de resolver sus problemas (Lancaster, 1992; Bowker, 1997; Von Soest, 1997; Alder, 2003). Se llega entonces a ver y actuar la violencia como algo limpio y normal en esencia. Para Brownell \& Roberts (2002), la socialización hacia la masculinidad apoya la violencia y la agresión para conseguir las metas y la expresión ritual de relaciones de poder entre los hombres. Tienden entonces a ver la violencia como el método preferido disponible para encarar conflictos entre individuos y grupos.

Los tipos de violencia que se generan a través de la estructura social pueden ir desde la omisión hasta la negligencia individual; la represión, vista a través de conductas como asesinatos y la negación de derechos, hasta la alienación, que se evidencia en casos como el de devaluar a la persona. Al respecto, 
Gil (1999) entiende que la violencia incluso inhibe el desarrollo de los individuos al impedir la ampliación de las necesidades humanas. En tal sentido, se comprende que las sociedades son violentas socio-estructuralmente cuando la desigualdad social niega los derechos de los miembros de la sociedad. La desigualdad social a su vez genera violencia estructural en la medida en que organiza socialmente los accesos a los bienes y servicios. Es decir, estigmatiza y limita los espacios de acción. Esto significa que, mientras mayores sean los niveles de desigualdad, mayores tenderán a ser los niveles de violencia. Entonces, se concretiza una vinculación de la violencia, tanto en hombres como entre mujeres, respecto a la creciente desigualdad generada en las ciudades y a la pobreza en particular. Con ello, los grupos en ventaja de las relaciones de poder definen la violencia de acuerdo a formas que legitiman su propio poder. Así, utilizan esas concepciones para reforzarse jerárquicamente. Esto significa que, a diferencia de algunos autores acá citados, las definiciones de violencia no descansan en los actos en sí mismos, sino en cómo los grupos aventajados en las relaciones de poder y autoridad conceptualizan estos actos de violencia. En última instancia, nos lleva a considerar que la propia estructura de poder tiene condiciones de legitimar la violencia que vivimos. Así visto, podríamos entender que los actos de violencia se pueden legitimar, validar o censurar de acuerdo a cómo se den las relaciones intersecciones de poder, raza, género y clase social y edad, entre otros.

Por otro lado, en el proceso de construcción de la masculinidad hegemónica entran en juego una serie de actores que la promueven y refuerzan. Tomemos por ejemplo a algunos sacerdotes, maestros, periodistas, propagandistas, políticos, psiquiatras, escritores, directores de películas, novelistas, músicos, activistas, académicos, héroes y hombres de deportes, entre otros. Esta masculinidad llamada hegemónica se materializa en los héroes que pasan a poblar nuestro diario vivir. Se evidencia que esa concepción contemporánea de lo que es la masculinidad ha estado intrínsecamente ligada a la visión de violencia y agresividad, a través de las cuales aprendemos a demostrar nuestra valentía y nuestras fortalezas como hombres, esto según Cruz, Fernández, González \& Román (1990). De igual forma, los referidos autores expresan que los mensajes predominantes que recibimos como hombres "nos recuerdan que, para ser masculinos, tenemos que ser dominantes y que la violencia y la agresión nos permitirán el control y la dominación" (p. 21).

\section{Procesos y tipos de violencia}

Los procesos a través de los cuales se desarrollan e incorporan los discursos y paradigmas que los apoyan son múltiples y de diversas complejidades. Estas complejidades circulan, se re-crean, se re-producen y se integran al cotidiano de las sociedades a través de múltiples procesos. Entre estos, sobresalen la socialización, la convivencia en grupos de pares -a diversos niveles y en diferentes contextos de nuestro desarrollo, procesos y experiencias programadas y otras coyunturales, pero debidamente pensadas-. Nada fuera de control de las estructuras en ventaja de las relaciones de poder. Estas se implantan a través de las propias estructuras sociales donde somos los actores en esta obra del teatro de la vida. Por así decirlo, nos movemos como individuos y como profesionales en campos minados donde al apalabrar o invisibilizar la violencia somos sus partícipes y promotores. En ocasiones, se llega al extremo de mimetizar las conductas propias de las personas a las que ofrecemos nuestros servicios profesionales, de lo que podemos encontrar mayor detalle en la Figura 4. Basta iniciar con el reconocimiento de las realidades y contextualizarlas para comenzar a ver cómo nos vamos a comportar a nivel personal y profesional. Es una experiencia de alto riesgo y llena de desafíos.

Otra dimensión de la violencia se vincula a su percepción desde el punto de vista del propio hombre y de su imagen. Al respecto, Dietz (1998) trae a colación datos de estudios que muestran que la masculinidad y sus estereotipos incluyen aspectos como la agresión, la independencia, lo dominante, la autosuficiencia y la falta de emotividad. Su preocupación fue más allá, al vincular la imagen del cuerpo y la autoestima de los hombres. Al estudiar la violencia y el género en los juegos de video, este mismo autor encontró que los medios de comunicación daban la impresión de que la violencia era el método más efectivo y preferible de resolver problemas; como si la violencia y la victimización fuesen componentes normales de la sociedad. El impacto de este tipo de análisis sobre el desarrollo de identidad de los niños es ciertamente preocupante y también afecta sus actitudes hacia la mujer. De acuerdo a Rodríguez (2013), algo tan cotidiano como los videojuegos generan otra dimensión hacia la violencia. A su entender, son los videojuegos lugares gobernables de la transgresión, una violencia accesible pero contenida, a la mano de los menores de edad, asunto que requiere discusión y acción inmediata. 
La violencia masculina podría incluso verse como un medio para mantener y reforzar su poder y a su vez una forma de control social (Alder, 2003). Ambos aspectos son relevantes a las manifestaciones de violencia de los hombres masculinos en instituciones penales. Por otro lado, un hombre que evidencie que puede controlar su violencia, puede y tiende a ser bien visto. Evidencia lo que fuera de ese contexto sería indiscutible al observador común.

La violencia, como hemos visto, ha sido estructuralmente vinculada a lo masculino y mayormente al hombre, donde se ve y estila como algo natural. Los incidentes de violencia masculina parecen activar su "macharranería". Al respecto, Messerschmidt (2001) ha llevado a cabo estudios que evidencian la alta relación entre masculinidad y violencia, especialmente en lo que se relaciona con crímenes. Por eso, una sociedad que establece o promueve fuertes vínculos entre violencia y masculinidad hace que la violencia que surja sirva en dos propósitos. Primero, el de construir una identidad masculina y heterosexual para los hombres violentos a través de envolvimientos simultáneos con la violencia. Segundo, tipifica a los homosexuales -subordinados- como un grupo externo y opositor que reta a la masculinidad hegemónica. Esta última masculinidad no se ve considerado como parte del conjunto de masculinidades según el Modelo de Masculinidad Hegemónica de Ramírez, García, Vélez \& Cunninghan (2002).

Esta violencia no es otra cosa que una expresión de poder, un arma de control social cuya función es la subordinación (Flood, 1997). La confrontación física entre los hombres es una forma de confirmación de la masculinidad, de poder, y establecer ese poder y de ayudar a mantener jerarquías en sus diversos niveles de acción. La violencia es pues una forma que sirve para probar las fuentes de la hombría, a las que se hizo referencia anteriormente. Este patrón se observa en el crimen masculino independientemente de la fuente de información, nivel de envolvimiento o medida de participación. Al respecto, Kimmel (2000), retomando planteamientos de otros estudios, expone que los hombres están más propensos a cometer actos criminales que las mujeres. Estas nociones son también apoyadas por Lancaster (1992), para quien la violencia es un asunto irreversiblemente masculino.

Un factor a ser considerado es que la masculinidad, por sí sola, no genera violencia (Krienert, 2003). El foco de atención está más en las formas aceptables de expresarse que tienen los hombres a nivel de la sociedad donde viven. La rudeza, el dominio y la voluntad de recurrir a la violencia para resolver conflictos interpersonales son características culturales de la identidad de género. Entonces se argumenta que el género es construido socialmente y existen diversos rasgos de masculinidad, lo que es clave para entender la violencia e intentar lidiar con ella más eficientemente. La socialización, la presión de grupos, los medios de comunicación y la mistificación de lo militar, entre otros asuntos, lleva al

CAMPOS DE LA ACCIÓN DE LA VIOLENCIA

\section{Consigo mismo \\ - Adicciones}

\section{Familia}

- Hogar - Pareja e hijos/as

\section{Comunidad}

- Con individuos selectivamente

\section{Grupos organizados y apodados por el Estado}

- Ejército, policía y otros semejantes

- Deportes, frente a TV y radio

- Agencias públicas y privadas, entre otras

Fuente: Elaboración propia (2017). 
comportamiento violento y con frecuencia criminal a ser aceptado, como lo es matar por la patria. En esta forma de representación del hombre, su dominio y su masculinidad hacen el camino hacia la violencia uno de apariencia "más fácil".

De acuerdo a Madrigal (2009), en los procesos de socialización de género y en la construcción de la masculinidad hegemónica, los hombres incorporarán creencias, valores y actitudes que en su configuración estereotipada constituyen la denominada mística masculina hegemónica, tan difícil de cuestionar, devaluar e intentar desmontar. Por otro lado, se argumenta que la falta de condiciones para obtener poder y beneficiarse del mismo hace que los hombres se sientan más vulnerables a ejercer su masculinidad compulsivamente, lo que puede resultar en comportamiento violento (Krienert, 2003). Es un recurso disponible -la violencia- para validarse como hombres masculinos y evidenciarse a través de su conducta como tales. La violencia al interior de las propias masculinidades es entonces campo fértil de actos de violencia impensables.

Nos preguntamos entonces en qué medida como profesionales de Trabajo Social analizamos los paradigmas y esos discursos que atraviesan los campos de interrelaciones masculinas como lo son los contextos familiares, comunitarios, escolares y laborales, entre otros. En qué medida hemos considerado con la seriedad necesaria que dentro de la familia convergen la mayoría de los discursos vigentes en nuestra sociedad, dando paso a la violencia en las relaciones de pareja y familia, entre otros. Los contextos penitenciarios ciertamente constituyen un espacio para reconsiderar las formas tradicionales de trabajo y hacer nuestro el reto de trabajar con los hombres privados de libertad desde una perspectiva de género masculino, aspecto que consideramos no ha sido de problematización especial por parte de la academia o de los profesionales del Trabajo Social. Esta desatención se traduce en intervenciones acríticas y desconocedoras de la relevancia de esta perspectiva.

\section{Masculinidades en el contexto institucional}

El objetivo fundamental de la prisión, su razón de ser, es vigilar y castigar (Foucault, 2009). La prisión se inserta de forma supeditada en la estructura económica de la sociedad, así ilustrado en la Figura 5. Es una institución consumista dentro de una perspectiva capitalista que también ha sucumbido al impacto de la globalización, el neoliberalismo y la privatización como su principal estrategia. Ac- tualmente en países como los Estados Unidos, la privatización de las instituciones penales está siendo cuestionada y de la misma forma el paradigma de la violencia criminal, una vez que la mayor parte de las poblaciones privadas de libertad no ha sido intervenida por crímenes violentos, lo que coloca en entredicho la necesidad de tantas prisiones y a su vez de sentencias severas (Harris, 2017). Genera empleos y con las políticas de privatización -fruto de la globalización- genera ganancias para las empresas que las administran sin colocar en la justa perspectiva el viejo paradigma de rehabilitación del confinado (Dammert, 2006).

En algunos casos, el Estado vinculado a la empresa privada podría castigar doblemente al preso, por ser prisionero y en gran medida por ser indigente. Se pregunta uno quien antecede a quien en la carrera por el bienestar del privado de libertad; el lucro empresarial o la responsabilidad del Estado por la reinserción social. Desde la perspectiva política, la prisión ofrecida por el Estado la torna en un espacio único en diversos sentidos, principalmente para almacenar un contingente humano -mayormente de hombres-. La prisión ejerce una función vital de control y encierro físico de personas mayormente jóvenes y hombres, que no son considerados económicamente productivos dentro de los parámetros aceptados por la sociedad y por lo tanto son dispensables, considerados invisibles para muchos, un ejército de mano de obra disponible a merced y disposición del Estado.

Los estudios de la estructura social de la prisión destacan que ésta se caracteriza por ser un ambiente de privación y vulneración de derechos humanos y civiles con diversos tipos de carencias para con la población penal. Es decir, coarta y reconstruye el mundo externo en que se apoyan las masculinidades, es un ambiente difícil para vivir como hombre (Sabo, Kupers \& London, 2001). Es un contexto que, a pesar de ser un microcosmos de la sociedad, es singularmente artificial y, como tal, sujeto a la manipulación intencional de los actores involucrados en nombre de la sociedad y la cuestionable moral pública que al respecto tiende a caracterizarlas. Con ello, estar preso tiene muchos significados, entre los cuales se destaca la pérdida concreta de la libertad y la paulatina distorsión de su significado. Ser un hombre que perdió la libertad implica la limitación de sus espacios físicos y sociales, los controles de sus movimientos, de ese merodeo característico de los hombres y la consideración tradicional de que "el hombre es de la calle". En suma, estar preso es la antítesis de ser hombre. 


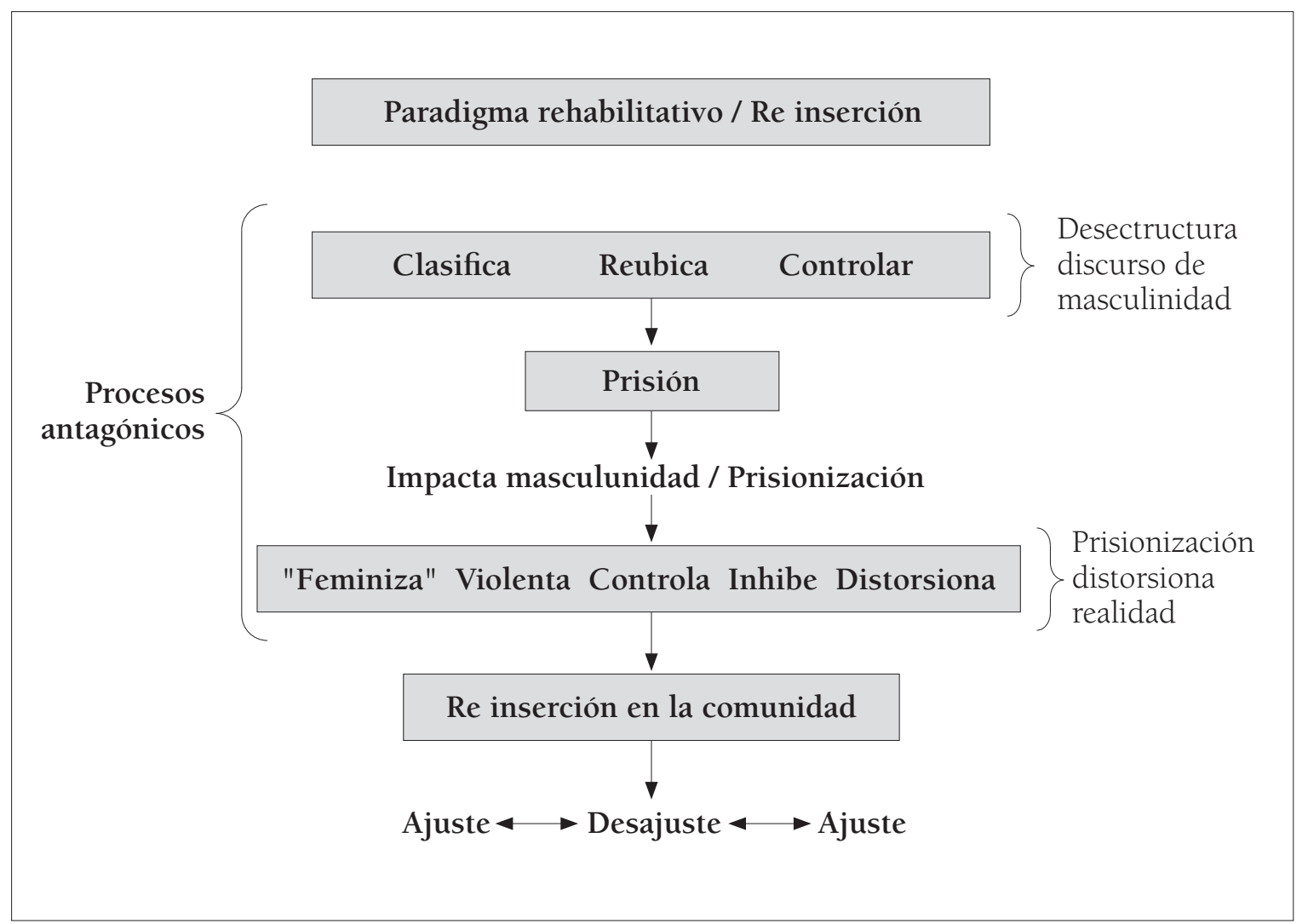

Fuente: Elaboración propia (2017).

La prisión emascula al confinado, le priva de su individualidad, lo homogeniza como preso (Phillis, 2001). Además, lo despoja de la identidad y masculinidad que le caracterizaba en la comunidad (Sim, 1995). Por así decirlo, lo "feminiza" y en parte lo castra socialmente como hombre. De otra parte, el cerco por el personal de seguridad y control hace que el prisionero se sienta constante y perversamente asediado. El privado de libertad se somete a un proceso de coerción y agresión que es proveniente tanto de sus compañeros de prisión como de sus captores, representados por los oficiales de custodia o guardias penales. Además, presentándose en algunos casos, el acoso sexual de parte de sus compañeros de prisión y en ocasiones de los oficiales de custodia incide sobre su masculinidad.

Esto ocurre en un medio mayormente homosocial donde unos confinados asedian a otros para dominarlos. Esto puede ser a través de la violación sexual o por algún tipo de subterfugio que los lleve a perder su estatus de hombres o a probarse como tales, dándose a respetar a toda costa, inclusive a través de la violencia física. Podríamos decir que, de modo general, uno de los aspectos de mayor preocupación para los hombres presos es la pérdida de la oportunidad de relacionarse heterosexualmente. En el ambiente homosocial y en ocasiones homoerótico de la prisión, no hay espacio (a no ser que sea a nivel de fantasías sexuales) para las relaciones heterosexuales, especialmente cuando en el contexto de muchos de nuestros países la visita conyugal no es permitida. Siendo así, la imposición sexual -por la fuerza y otros subterfugios- ofrece al que domina sexualmente a otro la capacidad de devaluar la masculinidad del poseído.

Una vez poseído, o sea penetrado, este hombre pasa a ser un subordinado, homosexualizado a los ojos de los otros. Se ubica en un estatus semejante al constructo predominante de la mujer, equivalente a una masculinidad subordinada. Este proceso impulsa el surgimiento de otras masculinidades en el contexto institucional, diferenciando los hombres y creando diversas categorías de identidades de género masculino y de identidad sexual. La dominación sexual sirve, además, para castigar a los "chotas" mercaderes de informaciones de cualquier tipo-, a 
los que "flirtean" y a los que se rebelan contra las jerarquías existentes (Schifter, 1998). El impacto del contexto prisional sobre la masculinidad produce -al igual que en el ámbito externo de la sociedaddistintas masculinidades (Sabo, Kupers \& London, 2001). Este ambiente es uno de jerarquías entre hombres que se dominan entre sí. Entre los presos existen élites o grupos organizados que ejercen dominio sobre la población a través de estatus y poder físico, entre otros medios disponibles.

El ambiente de la prisión genera violencia. Es un espacio de constante vulneración de derechos humanos y civiles, como lo ha sido el de privados de libertad que profesan la religión del islam en las prisiones de Puerto Rico (García, 2012). Este comportamiento violento en esas circunstancias se considera rutinario y normal. Con frecuencia, la institución sustenta, reproduce e intensifica los aspectos violentos de la masculinidad y al hacerlo moldea identidades y patrones de comportamiento. Existe evidencia de que el comportamiento de los internos en instituciones como las prisiones es también producto de las relaciones entre ellos, el personal de custodia y de la comunidad que les rodea. La administración inadecuada de instituciones penales es vista como una causa intrínsecamente promovedora de disturbios (Siegel, 1992). Las manifestaciones de violencia que surgen de la dinámica de relaciones interpersonales en la prisión no son necesariamente patológicas. Por el contrario, tal y como se mencionó anteriormente, son parte de una rutina acostumbrada, de su cotidiano.

La visualización de la violencia como algo patológico tiene varios efectos. Refuerza el discurso oficialista popular y profesional de fuertes bases neoliberales sobre las patologías individuales que tienden a implicar sin cuestionamiento que todos los privados de libertad tienen problemas de salud mental o están con algún tipo de condición de salud mental comprometedora. Consideramos que esto no necesariamente es cierto. A su vez tiene efectos marcados sobre los profesionales del Trabajo Social desconocedores de esta realidad, requiriendo de preparación para responder a tales efectos si están verdaderamente insertados en la cuestión social (Martínez, 2015). Apoya al Estado y a grupos de presión en la política de interés social de "mantener los violentos" fuera de circulación, o sea, en las cárceles y prisiones del país.

Los diversos tipos de violencia en la prisión se presentan como algo "normal" y legitimado y, al hacerlo, se validan las acciones de los representantes del Estado a través de políticas de seguridad exigen- tes. De esta forma, el debate de la violencia termina construyéndose en términos circunscritos a nivel individual y de su personalidad respecto a las masculinidades, mientras se produce en el cotidiano de la prisión la normalidad de la subordinación, el control y la humillación. La constante presión que reciben los hombres en la prisión para mostrar su masculinidad y, por ende, no evidenciar ningún rasgo de debilidad -lo socialmente asignado y relativo a lo femenino-, genera mucha tensión.

A su vez, al exacerbar los rasgos masculinos, muchos hombres se tornan hipermasculinos. Es decir, la hipermasculinidad, de modo general vinculada a los hombres jóvenes, es inminentemente resistente a la autoridad, a la cual reacciona con más violencia. Esto lleva a los hombres agresivos a ser más violentos y dejarse conocer en la población como hombres poderosos que no temen en imponerse física o sexualmente sobre la población (Toch, 1998; Ramírez, García, Vélez \& Cunninghan, 2002). Los hombres encarcelados tienen que respetar el llamado de los códigos de la prisión, donde se establecen los comportamientos permitidos y regulados por varios principios. Entre estos, se destacan los de respetar la jerarquía establecida de dominación y subordinación y aceptar que los que se ubican en la base de esa jerarquía son considerados como menos hombres. Estos últimos, generalmente son los homosexuales, los "chotas", los devaluados y los subordinados, entre otros. Adicionalmente, se exige el silencio, no delatar, no informar y aceptar calladamente el abuso de unos hombres contra otros (Levit, 2001). Estos códigos colocan a la población penal hacia la conformidad y aceptación de la estructura dual de poder dentro del contexto institucional, por un lado constituida por la oficialidad y, por otro, por los internos dominantes. De esta forma, se da mayor solidez a su control interno.

En tal sentido, al referirse a la construcción social de la masculinidad en la prisión, Phillips (2001) acuñó el término stand up man para destacar la necesidad de 'actuar' masculino para poder sobrevivir en la prisión. Este stand up man no se supone que socialice con los guardias. El contexto institucional fuerza a los hombres a actuar sus masculinidades, a reconstruir sus identidades y sus estatus. Los lleva a representar una adaptación al ambiente, donde el control interno de los recursos es limitado, donde el peligro puede ser extremo y la privación grande. De tal forma, lo antes expuesto ciertamente incide negativamente a varios niveles. Es decir, impacta a nivel de tratamiento, al camuflar el comportamiento a ser trabajado y, en segunda instancia, al promover 
espacios de confrontación con los guardias y con la propia población que reacciona a las diversas actuaciones o "frontes".

La prisión contribuye al desarrollo de una masculinidad cómplice de la variante hegemónica, esto porque promueve el dominio del hombre, la heterosexualidad, la violencia y la competencia desmedida (Sabo, Kupers \& London, 2001; García, Ramírez \& Solano, 2007). Dentro de esta perspectiva, el crimen y la violencia se ven como prácticas sociales a las cuales recurren y podrán recurrir los hombres presos, como un recurso para complementar sus masculinidades, en un ambiente que los reta en lo que a ser hombre se refiere. En este sentido, se promueve la reproducción de las inequidades, desigualdades y se permite el desarrollo de una elite criminal que puede llegar a tomar el control del contexto donde se insertan.

Las anteriores circunstancias ciertamente son un desafío para el Trabajo Social, ya que se presentan implicaciones, no solo de las dinámicas estructurales y efectos entre los profesionales, sino y principalmente por los efectos sobre los seres humanos aquí retenidos. Estas situaciones peculiares nos imposibilitan cuestionar ante una posición sumamente compleja y, por demás, comprometedora. Acá, nuestros principios éticos profesionales se ven fragilizados y necesitados de que como profesionales y como profesión asumamos posturas que nos representen y nos validen como defensores de los derechos humanos, esto por mencionar algún aspecto fundamental del Trabajo Social.

\section{Prisiones: Paradigmas de tratamiento cuestionados}

La prisión es el contexto donde a través del tratamiento se implanta el paradigma de la rehabilitación del confinado(a), lo que, ciertamente, tiene sus efectos sobre las masculinidades. Es decir, el propio paradigma de la rehabilitación, fruto del positivismo, genera en este análisis una paradoja. Esto es así pues el tratamiento a nivel institucional se da desde un contexto caracterizado mayormente por el encierro y el control institucional, que puede inclusive llegar hasta la tortura (Norris, Larsen \& Stastny, 2010; Gaiak, 2010). Así, se espera que, apoyada en profesionales de la conducta, la propuesta de rehabilitación, ahora conocida como de reintegración o inserción social, se vea cuestionada desde la perspectiva de su propósito o meta principal.
Actualmente no existe consenso a nivel académico, legal y entre profesionales de la conducta en cuanto a los efectos y virtudes del paradigma de rehabilitación. Lo cierto es que la mayor parte de los estudios relacionados a crimen, la criminalidad, los sistemas penitenciarios y los tratamientos variados se debaten entre el reconocimiento a la posibilidad de que la prisión pueda rehabilitar y aquellos que la consideran un contexto superado, contradictorio e inadecuado que no provee espacio a tales efectos y que merece desaparecer como opción del Estado (Torres, 2014). El trabajo de Willliamson (2005), donde expone este problema en Chile, nos alerta sobre las políticas y programas de rehabilitación.

Con ello, hace referencia al choque en los USA entre las doctrinas de nothing works -nada trabaja- vs what works -lo que trabaja- donde se evidencian las tendencias respecto a tratamiento penitenciario, dejando entrever espacios grises al respecto. De esta forma, nos hace una serie de recomendaciones muy pertinentes a considerar para que los programas de rehabilitación también puedan ser efectivos. A pesar de esto, una gran mayoría de estos estudios vislumbran que se puede rehabilitar o reinsertar socialmente, como se intenta reconceptuar ese proceso actualmente. Entendemos que el tratamiento dirigido a los privados de libertad y la filosofía institucional basados en el paradigma de la rehabilitación deben focalizar sus esfuerzos y energías hacia la integración y no al castigo y a la eventual reincidencia como evidencia del fracaso del sistema (García, 1982; Moon, Sundt, Cullen \& Wright, 2000; Steele \& Wilicox, 2003; Cullen, 2005; Sounders, 2006; Travis \& Petersilia, 2007).

Para Travis \& Petersilia (2007), el tratamiento debe corresponder a una política uniforme de tratamiento, algo que en los últimos años ha venido a ser cuestionado. Sustentan también que el tratamiento debe ser voluntario para ser efectivo. O bien, como decían Hood \& Sparks ya en la década de 1970, el tratamiento penitenciario para que sea efectivo debe ser promovido a través de un proceso conocido como de cambio facilitado -entiéndase motivado- pero nunca impuesto. Se parte del principio básico de que, si bien es cierto, la filosofía de tratamiento debe permear a todos, no necesariamente por estar internado se necesita tratamiento. Cullen (2005) y Hanley (2006) sugieren que el tratamiento penitenciario se apoye en estudios recientes al respecto, desarrollados por criminólogos y otros

2. Frontes - puertorriquenización del anglicismo "front". Se refiere a actuar la situación o circunstancia; en este caso, a actuar su masculinidad, dejarla evidente a través de acciones, gestos o mímicas, en ocasiones exageradas. 
expertos de área, que han sido validados. Aducen estos estudiosos que existe suficiente conocimiento criminológico como para apoyar y garantizar el éxito de determinados programas. A su vez, otros promotores del tratamiento entienden que se debe trabajar con valores la educación de los internos (Moon, Sundt, Cullen $\&$ Wright, 2000) y el problema de drogas a nivel de uso y abuso.

En tal sentido, este problema por su complejidad e implicaciones que tiene para el contexto debe ser tratado inicialmente por su carácter comprometedor para asumir cualquier otro tipo de tratamiento (Knight, Garmen, Simpson, Diyaym \& Flynn, 2006; Sounders, 2006; Nelson, Specian, Campbell \& De Mello, 2006; Albizu-García, 2007). La existencia entre las poblaciones penitenciarias del uso de drogas y la consecuente adicción que estas traen consigo evidencia efectos adversos. Entre estos, está la constatación de más de un diagnóstico clínico, lo que dificulta el manejo de cualquier tipo de atención o tratamiento para con esta población. Básico al trabajo con privados de libertad en estas circunstancias es que, previo a iniciar cualquier tratamiento, se debe trabajar con las adicciones y otros diagnósticos clínicos que faciliten el proceso de rehabilitación en cualquiera de sus modalidades (Sounders, 2006; Taylor, 2007; Immagerion \& Greene, 2008).

Fue curioso constatar cómo la mayor parte de estos estudiosos coincidieron en aspectos vinculados a la importancia del tratamiento, como lo es basar el tratamiento en las necesidades criminológicas del interno y sobre todo que fuese sensitivo en aspectos de género (Spiropoulus, Spruance, Von Voorhis \& Schmitt, 2005). De igual forma, apoyar la educación vocacional en programas de componentes múltiples que consideren industrias penales, apoyo al empleo y desarrollo de programa con el apoyo de la comunidad (Bouffort, Mackency \& Hickman, 2000).

Las investigaciones que tuvieron preocupaciones serias respecto a la idoneidad de las estructuras penitenciarias para apoyar el paradigma de la rehabilitación incidieron en aspectos como la falta de apoyo práctico del personal de custodia (Schaufeli \& Peeters, 2000); problemas de fragmentación filosófica (Travis \& Petersilia, 2007). También sobresalió la incapacidad para lidiar con el crítico problema de salud mental (Pérez, Leifman \& Estrada, 2003); necesidad de trabajar con la dimensión de la masculinidad en la posible rehabilitación (Steele \& Wilicox ,2003); propensión del ámbito de la prisión a promover la depresión de los internos y el hecho de considerar este ambiente poco favorable, promovedor de estrés y de un sinnúmero de problemas que conspiran para contrariar el éxito del tratamiento.

Adicionalmente, emerge la preocupación con la delicada consideración entre componentes del contexto prisional, la propensión de los internos y el régimen propuesto por la cultura institucional que emerge (Camp \& Gaes, 2005). También, la prisionización que emerge en la población es contraria al tratamiento por sus aspectos adversos a nivel de la estructura de personalidad (Ortmann, 2000); el hecho de que muchas prisiones no pasan de ser un local para el almacenaje de personas con conductas criminales es contrario a la noción de tratamiento y rehabilitación. Se agrega el refuerzo que el ambiente de prisión hace sobre lo masculino y su impacto negativo en la disposición hacia la búsqueda de ayuda (Williams, Skogstad \& Deane, 2007). Finalmente, se vuelven a traer a colación los aspectos de la depresión, al impedir los hombres de pedir ayuda, sumado al impacto de los discursos de la masculinidad (Scelfo, 2007).

De igual forma, otros autores señalan aspectos de política pública que resultan, además de los ya mencionados, muy importantes. A saber, la necesidad de cambios de paradigmas para abordar el fenómeno criminal y, principalmente, para reenfocar la presencia del tratamiento en este contexto (Moon, Sundt, Cullen \& Wright, 2000). También, la opción de trabajar con paradigmas y propuestas alternas que nos ayudaran a apoyar la gente, reforzándose en este caso, la educación, variable considerada de suma relevancia (Eisner, 1990). Con ello, resulta necesario promover el desarrollo de programas y servicios para que traten el creciente problema de salud mental en las prisiones y evitar a su vez la criminalización de la salud mental y de las personas que a su vez la padecen (Pérez, Leifman $\&$ Estrada, 2003). De igual forma, es importante basar el tratamiento penitenciario en estudios y en conocimientos criminológicos desarrollados por estudiosos del área (Cullen, 2005), evitando así la improvisación y los efectos adversos sobre la población y la comunidad a donde retornan los privados de libertad.

En tal sentido, profesionales del Trabajo Social se insertan en los programas creados para ofrecer tratamiento a la población penal. A los profesionales que trabajan en los escenarios relacionados con la evaluación o servicios hacia las personas acusadas o penadas de delitos se los reconoce como profesionales de Trabajo Social en contexto criminológicos 
o Trabajo Social criminológico (Kester, 2007). La concepción general es que este ejercicio se remite al ambiente penitenciario, pero nuestra profesión, como interventores sociales en las políticas criminales y penales, nos permite estar inmersos en los procesos previos a las penas privativas de libertad, como en el proceso jurídico. Incluso, como profesión nuestro alcance va más allá, llega a momentos remotos a la realización de algún acto criminal o delictivo. Nos encontramos en los escenarios escolares, salubristas, clínicos, comunitarios, en los cuales nos exponemos a historias de vidas de sujetos sociales con altas probabilidades de terminar en alguna prisión por sus circunstancias e historia de vida.

El Trabajo Social ha ido articulándose como una profesión en defensa de los derechos humanos de aquellos sujetos sociales con los cuales trabajamos y con todos los que viven y -de modo general- sufren las discriminaciones, injusticias y desigualdades sociales. Entonces, con esta filosofía es cuando en el contexto sociojurídico y penitenciario nos enfrentamos a grandes retos como, por ejemplo, trabajar en defensa y beneficio de aquellas personas a quienes se les ha juzgado por realizar alguna actividad delictiva o ilícita. Para quienes tienen una visión legalista de lo social, realizar este trabajo sería para sí contradictorio y podría resultar en contradicción a la defensa de los derechos humanos de esta población. En las prisiones, el profesional de lo social se encuentra en la atención de los reclusos durante su ingreso, en el proceso de acompañamiento en el tiempo de privación de libertad y finalmente en su egreso (Cedeño \& Monge, 2011). En estas instancias se puede realizar una práctica sociocriminológica tradicional o una crítica, lo cual es resultado de la formación del o la profesional, de los paradigmas del tratamiento, de las políticas institucionales y sociales que guían el ejercicio profesional. La práctica tradicional en el contexto criminológico tiene fundamentos positivistas y lleva a ver a la persona desde una visión biológica y patológica, individualizando las acciones delictivas (Kester, 2007). Esta crítica rompe con las viejas concepciones de la criminalidad y centra su foco de análisis en el control social.

Si la visión de la política social es de "mano dura contra el crimen", "cero tolerancia al criminal", "mayor pena para el delincuente", "la criminalidad es un problema de salud mental", entonces, como profesionales ejecutores de estas políticas, nos encontraremos con programas que explícita o implícitamente lleven esta idea a la práctica del tratamiento o servicio. Entonces, como profesionales, nos vemos entre la visión punitiva e institucional de vigilar y castigar al recluso versus el principio de búsqueda de un trato humano basada en el cumplimiento de los derechos de la población reclusa.

De igual forma, los derechos humanos de la población penitenciaria han sido tema de discusión internacional, en particular desde la Organización de las Naciones Unidas (ONU). En la creación de los derechos humanos universales, encontramos que tres de ellos son relativos al trato hacia los privados de libertad. Con estos, se condena las torturas, los tratos crueles e inhumanos, se prohíbe las detenciones arbitrarias y se eleva la presunción de inocencia. A mitad del siglo anterior, dos años luego de la Carta de Derechos Humanos, la ONU reconoce un organismo para trabajar explícitamente con los derechos de la población penal. A partir de estos trabajos se han creado reglas y principios que sirven como guías para el trato justo y humano de los reclusos (Rodríguez, 2011), siendo una de las más prominentes "las reglas mínimas para el tratamiento de los reclusos" creadas en 1957.

Según Coyle (2002), otras herramientas que han sido creadas son el conjunto de principios para la protección de todas las personas sometidas a cualquier forma de detención o prisión (1988); los principios básicos para el tratamiento de los reclusos (1990) y las reglas mínimas de las Naciones Unidas para la administración de justicia a menores (1985). También se ha creado por la ONU (2005) el manual de bolsillo de normas internaciones de derechos humanos para funcionarios de instituciones penales. El International Centre for Prision Studies ha creado el Manual para el Personal Penitenciario, Administración penitenciaria en el contexto de los derechos humanos. Con esto, ya los profesionales de Trabajo Social tenemos una base filosófica y jurídica internacionalmente que puede guiar nuestros acercamientos hacia unos enmarcados en los derechos humanos y encaminarnos hacia unos fundamentos teóricos y metodológicos críticos en el contexto penitenciario y sociojurídico.

Existe el fundamento teórico y práctico que, como profesionales del Trabajo Social, nos lleva a comprender que las políticas punitivas y torturantes no aportan a una sociedad más segura, que se hace

\footnotetext{
3. Política pública de seguridad en el contexto de Puerto Rico que ha estado vigente durante más de dos décadas, aproximadamente, y que intenta responder al aumento de la criminalidad y la violencia en el país. Evidencia el fenómeno de la aplicación de políticas públicas de los EE.UU. sobre las políticas locales y en ocasiones en niveles descontextualizados.
} 
cada vez más necesario integrar paradigmas que vayan a la luz de analizar críticamente los actos delictivos y llevar a la población reclusa a comprender las razones por las cuales llegan a ese espacio. Todo enmarcado en el derecho a la dignidad del ser humano, la cual no se pierde al ser condenado o sentenciado con una pena de reclusión. Un acercamiento desde una perspectiva crítica y un análisis del género masculino, basado en los derechos humanos, permitiría incidir en los cambios de enfoque del tratamiento hacia los hombres privados de libertad, al igual en reformular las políticas sociales para prevenir y disminuir la violencia.

De acuerdo a García (1999), el quehacer del Trabajo Social a nivel institucional debe reconsiderar seriamente los aspectos de los discursos y paradigmas, resaltando entre otros el discurso de la masculinidad hegemónica. Basándose en esta premisa y en el "quantum" de responsabilidad de los involucrados en el proceso, Sounders (2006) sugirió que todo modelo de tratamiento a nivel de instituciones penitenciarias debería constar de los aspectos detallados en la Tabla 1. Desde la perspectiva del Trabajo Social, todos estos aspectos deben ser evaluados críticamente en apoyo a la defensa de los derechos humanos y civiles y reforzados a su vez por el código de ética de los profesionales.

TABLA 1

FUNDAMENTOS MODELO DE TRATAMIENTO PARA INSTITUCIONES PENITENCIARIAS

Un sistema de clasificación adecuado que facilitase el poder de parear las situaciones particulares de los internos con los programas requeridos;

Promover el orden dentro del contexto institucional que a su vez facilite el desarrollo de los programas y servicios requeridos;

Promover la seguridad necesaria al buen y balanceado manejo de las dinámicas generadas por la cultura institucional;

Desarrollar buenos programas que responda a las necesidades de la población internada atendiendo los problemas de forma priorizada;

Establecer como meta de la efectividad del tratamiento institucional la reintegración a la comunidad, tomado como focos de atención el interno, su familia y la comunidad;

Apoyar todo el trabajo en una filosofía de rehabilitación y no de represión.

Fuente: Elaborado a partir de Sounders (2007).
Para finalizar resaltamos las preocupaciones elaboradas por Gil (1999) y García (2012), que hacemos nuestras. Nos referimos a la necesidad de autorreflexionar críticamente sobre la violencia de origen estructural, los patrones de opresión que tradicionalmente han incidido sobre las poblaciones que con mayor frecuencia forman parte de los contextos penitenciarios. También analizar las desigualdades sociales y económicas, la violación de derechos humanos y civiles, los abusos de poder a los que con frecuencia reaccionan adversamente los sistemas penitenciarios; de la misma forma, sobre los efectos adversos de los nuevos modelos económicos que inciden negativamente en nuestros países como el neoliberalismo, la globalización y la estrategia de privatización. Ejemplo de esto es el impacto negativo de la privatización de las instituciones penitenciarias donde confrontan dos discursos. Estos son el fin de lucro versus el descargue de la responsabilidad social del Estado. Para esto, véase el caso cada vez más crítico de la situación de las prisiones en países como los Estados Unidos (Harris, 2017). Ciertamente se hace necesario considerar el enfoque de género masculino cuando nos proponemos trabajar con hombres en las prisiones. Esto es así, por el efecto adverso del paradigma de la rehabilitación en el contexto prisional y principalmente sobre las masculinidades. Las contradicciones del primero tienen efectos negativos en la propuesta, el contexto y en las expectativas respecto a estos hombres que se someten al encierro con el propósito de pagar una deuda de la sociedad y para ser preparados para volver a la comunidad y al contexto de la libertad.

\section{Fenómeno de la prisión y el trabajo social: algunas consideraciones}

Reconocemos entonces que tanto los paradigmas como los discursos son básicos a toda propuesta de tratamiento en los contextos prisionales, haciéndose necesario identificarlos y analizarlos críticamente para poder entender sus efectos, en especial sobre los hombres y sus masculinidades. Al final de cuentas, la orientación de los sistemas penitenciarios no surge de la nada. Tal y como se muestra en la Tabla 2, desde el enfoque restaurativo de Unbriet (1996), se recomienda una serie de aspectos en ser considerados por los sistemas de justicia. La relevancia de este enfoque, al cual suscribimos, se basa en la importancia de la deconstrucción de principios, conceptos, paradigmas y discursos que se asumen como básicos sin cuestionamiento ni la debida colocación en perspectivas de estos con relación a la propuesta básica de la noción del encierro, aspecto que con frecuencia aceptamos de forma acrítica. 
TABLA 2

\section{CRITERIOS DEL ENFOQUE RESTAURATIVO EN LOS SISTEMAS DE JUSTICIA}

Definir el crimen como una violación contra la
persona y no contra el Estado;

No se debe imponer castigo y sí la restitución. La meta debe ser la reconciliación/restauración;

Justicia definida con relaciones adecuadas y juzgada por resultado o producto;

El crimen debe ser visto como conflicto interpersonal y no como conflicto entre individuo y Estado;

Foco de atención en la reparación social; Comunidad como ente facilitador y no como obstáculo;

Promoción de la mutualidad;

Tanto el ofensor como la víctima deben participar de la solución del problema;

Entender que el crimen y la violencia no son por naturaleza masculinos.

Fuente: Elaborado a partir de Unbriet (1996).

A título de recomendaciones, proponemos cinco aspectos que consideramos inciden en la vulneración de derechos humanos y civiles, lo que podría servir de orientación al momento de nuestro ejercicio profesional. A saber:

Derechos humanos y civiles. La constante y persistente vulneración de derechos sobre las poblaciones privadas de libertad en las instituciones penales y los programas que ofrecen están estrechamente vinculados a diversos aspectos. Entre estos, la rigidez usual de los sistemas penitenciarios apoyados por los sistemas de justicia y sus respectivos códigos; la ambigua moral social referente a la reinserción social de estas poblaciones. Es decir, de modo general son consideradas como problema de la sociedad y, por tanto, no merecedoras de mayores consideraciones por sus conductas. De igual forma, se caracteriza por un apoyo presupuestario que propenderá a la existencia de recursos, colocando en entredicho la propia meta del sistema según existe. Desde esta perspectiva la modificación de conductas, sus ajustes y preparación para salir de este sistema están carentes de valía social y de apoyo económico justificados por las leyes y la moral social imperante, constituyéndose en violencia estructural en el sentido más amplio de su palabra (García \& Cintrón, 2012).

Estudios y análisis críticos recientes han evidenciado estas prácticas de violación de derechos bajo el manto de la custodia y el control a través de las estructuras del Estado (American Civil Liberties Union -ACLU-, 2006) y como petición de los propios privados de libertad (García, 2012b). Ciertamente estos estudios constatan la crudeza de la cotidianidad de estas poblaciones cautivas que sufren y en ocasiones no consiguen identificar de dónde provienen, llegando a asumirlas como consecuencias de sus propias acciones. Violencia estructural invisibilizada, manejada como parte de las dinámicas institucionales. ¿Podemos como profesión ser partícipes de la violación de los derechos humanos de nuestros participantes o clientela o estamos ante una situación crítica de violación a nuestros propios principios éticos base de nuestra profesión sin reaccionar?

Envejecimiento de las poblaciones penales. El curso normal del proceso de envejecimiento de los seres humanos adquiere otra dimensión al considerar las instituciones penales y la complejidad cotidiana de las dinámicas de convivencia a su interior. Un estudio realizado por la ACLU (2012) alarmó al exponer una realidad por demás preocupante en el contexto del sistema penitenciario de los EE.UU. y Puerto Rico. Esta situación, que es común a todos los países de mundo con estos tipos de sistemas penitenciarios y de justicia basados en el cumplimiento de penas de prisión largas, como alternativa al manejo de la criminalidad creciente, está haciendo ver las crisis y las contradicciones que carga consigo misma, como consecuencia de las políticas de seguridad y encierro que promulgan e implementan. Para el periodo de tiempo que señala el estudio, se confirma que los EE.UU. tienen la mayor población penal del mundo con alrededor de 2,3 millones de individuos en encierro -mayormente hombres-, de los cuales la media de edad es de 50 años o más. Esto parece ser considerado por muchos como almacenes de personas envejecientes. El costo de uno de estos internos envejecientes es de aproximadamente 62.270 dólares al año o más, cuando el ingreso promedio de una familia en ese país es de 40.000 dólares.

Este fenómeno, que responde al desenfrenado pro- 
ceso de criminalización de conductas y al encierro en instituciones penales como la alternativa más común para cumplimiento de sentencias de infractores con penas cada vez más largas y complejas, ha evidenciado uno de sus más morbosos efectos. Con ello, zalguna vez alguien pensó o consideró a corto, mediano o largo plazo las implicaciones presupuestarias de estas políticas para la sociedad? ¿De quién es la responsabilidad de asistencia a estos envejecientes con múltiples y severas condiciones de salud aceleradas por los contextos institucionales? ¿del Estado, familia, colegas de prisión o de la comunidad? ¿Contamos en el contexto actual con el presupuesto necesario para tales requerimientos? ¿Se pensó en términos penológicos, criminológicos, legales y desde las profesiones de la conducta en cómo enfrentar el impacto de las condiciones de deterioro de estas poblaciones o se le va a repasar a las familias, las comunidades y a las famosas iniciativas publico privadas cuya meta es el lucro?

De más está considerar la necesidad de analizar críticamente los discursos y paradigmas que orientan y que son, sin duda, base y guía de esta situación que se ha salido de control desproporcionadamente y que continúa creciendo. Se cuestiona uno no solo la pertinencia de insistir en la aplicación de penas largas de prisión como el disuasorio por excelencia versus la necesidad apremiante necesidad de buscar alternativas a la pena de prisión (Torres, 2014). La vida humana, sujeto de la acción legal del Estado y el impacto del encierro, nos coloca de frente a un serio dilema profesional y es el respeto a la dignidad del ser humano y de sus derechos correspondientes. Esta situación nos coloca entre el cuestionamiento básico de la aceptación acrítica de insertarnos en estos escenarios lo que requeriría de nuestra parte el asumir posturas de avanzada, críticas y alternativas para poder justificar nuestro quehacer profesional.

Derecho al ejercicio de prácticas religiosa no tradicionales a los sistemas penitenciarios de nuestra región. Visto como uno de los componentes de cualquier modelo de tratamiento penitenciario -la religión- que se considere adecuado, la posibilidad de practicar la religión de preferencia de las poblaciones privadas de libertad, representa una garantía necesaria de parte del Estado. El surgimiento de nuevas modalidades religiosas, como la práctica del Islam, ha causado recientemente problemas en nuestro contexto nacional. A través del Observatorio Correccional, la Dra. Rivera, como parte de la Comisión de Derechos Civiles de Puerto Rico (CDC, 2009), del cual el autor principal fue coordinador por tres años, constató, a petición de cartas por par- te de la población en encierro, la vulneración de ese derecho fundamental y la necesidad de llevar a cabo un estudio para corroborar la existencia o no de este discrimen desconocido hasta entonces.

Luego de las investigaciones pertinentes y a través de las visitas a las instituciones penales concernidas se corroboró que se estaban negando sus derechos a participar de los rituales de su religión como también se les estigmatizaba personal y grupalmente y se les negaban los servicios médico-sociales solicitados por insistir en usar los símbolos de su religión. Inclusive se les negaba el derecho a reunión y a la orientación del Imán. La razón principal era la discriminación no solo contra sus prácticas sino contra todo lo que pareciera musulmán y su vínculo -según lo apalabraron- con el terrorismo. Los grupos cristianos, por el contrario, contaban con todo el apoyo de la administración institucional (CDC, 2011). Vulneraciones de derecho de este tipo evidencian la necesidad de que los profesionales de Trabajo Social estén atentos y vigilantes al impacto de situaciones emergentes que evidencien cómo la coyuntura actual incide sobre estas instituciones que son sin duda un microcosmos de la sociedad mayor. Su rechazo con el apoyo institucional expone de la misma forma la violación de derechos civiles y el discrimen desde las estructuras del Estado a lo que no podemos darle espacio. Nuestra acción es ciertamente un espacio irrenunciable.

Impacto de la tecnología de las comunicaciones en el cotidiano de las instituciones penales. Por ser parte integrante de las sociedades donde se insertan las instituciones penales, estas no son inmunes a los avances de la tecnología de las comunicaciones. Estos avances han traído una serie de repercusiones que inciden en las dinámicas de los contextos institucionales. Se destaca entre estos el uso de celulares o móviles. Estos, al ser una forma de comunicación cada vez más popular, sofisticada y accesible, han hecho su presencia evidente en las instituciones penales a todos los niveles teniendo un impacto severo sobre la cotidianidad institucional, pero más seriamente sobre la seguridad. De esta forma, los tradicionales códigos de comunicación y diálogo entre las poblaciones en encierro -sin haber desaparecido del todo- se han sofisticado, complejizando el control y sus estrategias tradicionales. Las formas de comunicación silenciosas y eficientes que tradicionalmente se les reconocía a estas poblaciones se han visto sujetas a cambio en respuesta a la tecnología

Por otro lado, tenemos la internet. Recientemente, esta se ha incorporado con relativo éxito en las ins- 
tituciones penales como apoyo al tratamiento -en la comunicación familiar-, especialmente cuando median grandes distancias entre las instituciones penales y las familias de las poblaciones confinadas al interior del país o fuera de este. Se cuestiona su efectividad por considerársele un medio frio, distante y sujeto a la intromisión de otros agentes del personal. Esta circunstancia, como sabemos, incide en la confidencialidad y otros asuntos como la violación de sus derechos humanos y civiles de estas poblaciones. Así, nos preguntamos icómo ajustar a los individuos a la poca y controlada comunicación interpersonal, cada vez más valorada en el mundo globalizado, en este contexto institucional? ¿Qué efectos trae esa dimensión tecnológica sobre la acción profesional del Trabajo Social? ¿Cómo podemos trabajar y posicionar nuestro quehacer entre el control y los adelantos tecnológicos y los posibles efectos a pesar de la seguridad y control fundamentales de las instituciones penales?

Alternativas a la prisión. Este asunto va desde la problematización y análisis crítico de las filosofías prevalecientes de castigo, ya cuestionadas por demás, versus las nuevas filosofías y discursos emergentes que reclaman menos prisión o su eliminación como la alternativa final. La justicia restauradora emerge como alternativa de mayor consonancia con los principios de la profesión de Trabajo Social lo que merece atención esmerada (García, 1999; Torres, 2014).

Lo que entonces queda sobre el tintero es qué se hará para ser coherente en la rehabilitación de los hombres bajo encierro en instituciones penales, en términos de las contradicciones y aspectos contraproducentes y generadores de tensión y mayor violencia, entre el paradigma y discurso de la rehabilitación y el discurso de la masculinidad hegemónica y sus exigencias. Rehabilitar es contrario a castigar/encerrar/controlar y subordinar que es lo que de modo general ocurre con nuestros casos de hombres internados. Esta situación paradójicamente conflictiva deja un espacio válido de autorreflexión a retomarse bajo otras perspectivas más apropiadas a la propia propuesta de reinserción social, tal vez bajo nuevos paradigmas cónsonos con las expectativas de género que a su vez requieren de la misma forma de profunda reflexión desde la perspectiva del Trabajo Social en el contexto penitenciario.

\section{Conclusiones}

Los discursos, la violencia y paradigmas de las masculinidades en las instituciones penales requieren de una atención redoblada por las implicaciones del contexto social. Ante lo presentado, es menester que estemos alertados a la apremiante necesidad de considerar críticamente lo importante que resulta generar nuevos lenguajes, conceptos, paradigmas y discursos, además de teorías. Esto con la intención de dirigirnos a nuevos significados para tratar de explicar las realidades cambiantes que están vinculadas a las poblaciones privadas de libertad y su relación con el Trabajo Social dentro del contexto penitenciario. Es decir, una nueva mirada desde un Trabajo Social transformador se hace necesaria. Es hora de pensar que no es hábil aceptar acríticamente las implicaciones en nuestro ejercicio profesional de estas políticas cuando lo que se espera es que las cuestionemos y descubramos sus pretensiones.

Considerando que la violencia no es un fenómeno necesariamente personal sino de estatura global, es importante que el Trabajo Social pueda no solo apalabrar sino desarrollar las estrategias necesarias para comprenderlo, analizarlo e intervenirlo, teniendo como meta final el bienestar de las poblaciones para quienes sirve. No podemos sucumbir a la noción neoliberal de la violencia individual en aras de no colocar en perspectiva el impacto de la violencia sobre las poblaciones, principalmente aquella que han sido tradicionalmente oprimidas y excluidas por la sociedad y por las estructuras con mayor ventaja en las relaciones de poder. Nuestro código de ética y las nociones de un Trabajo Social situado y consciente de la importancia de la dimensión social hace que nuestro quehacer sea cada vez más importante y de relevancia para con estas poblaciones.

Teniendo en consideración lo antes expuesto y a título de reflexión final, debemos desafiarnos hacia el desarrollo de una perspectiva de enfoque de un Trabajo Social penitenciario renovado y abocado a la transformación, con un profesional consciente de la perspectiva de género y, en este caso específico, conocedor del discurso de la masculinidad hegemónica. Esto le permitirá trabajar críticamente con las poblaciones bajo la atención del sistema penitenciario y otros sistemas correlacionados. Una profesión que sea conocedora de la importancia de las políticas públicas y su implantación; en este caso particular, de las políticas públicas de seguridad que inciden sobe las poblaciones bajo nuestra atención. Nos referimos a un Trabajo Social que evidencie respecto a la diversidad humana, libertad de expresión, respeto a los derechos humanos, sociales y culturales. De la misma forma, luchar por el derecho a la igualdad, equidad y al trato justo de la sociedad por parte las instituciones a las que se les someten. Fundamental a este trabajo y al enfoque 
que se ha desarrollado es la propuesta de un Modelo de Atención Penitenciario con un apoyo teórico práctico que promueva la filosofía de la reintegración social, justicia restauradora y de un Modelo Penitenciario Mínimo.

\section{Referencias bibliográficas}

ALBIZU-GARCÍA, C. (2007). Estudio de necesidades de tratamiento para abuso/dependencia a drogas y prevención de Hepatitis B/C en las prisiones de Puerto Rico. Centro de Investigación Sociomédica del Recinto de Ciencias Médicas. San Juan: Universidad de Puerto RIco.

ALDER, C. (2003). Exploring Violence. Socioeconomics and Masculinity. Recuperado de Criminal Justice System of Autralian Government: http://www.aic.gov.au/publications/aust-violence-1/Alder.pdf. p.p. $161-175$.

AMERICAN CIVIL LIBERTIES UNION (ACLU), (2006). Custody and Control. Conditions of Confinement in New York's Juvenile Prisions for Girl's. New York: ACLU.

AMERICAN CIVIL LIBERTIES UNION (ACLU). (2012). At America's Expense: The Mass. New York: ACLU.

ARENDT, H. (2006). Sobre la Violencia. España: Alianza Editorial

BOUFFORD, J., MACKENZIE, D., \& HICKMAN, L. (2000). Effectiveners of Vocational Education and Employment Programs for Adult Offenders: A Methodology -Based Analysis of the Literature. Journal of Offender Rehabilitation, 1(31), 1-41.

BOWKER, L. (Ed.). (1997). Masculinities and violence. Thousand Oaks, CA: Sage.

BROWNELL, P., \& ROBERTS, A. (2002). Century of Social Work in Criminal Justice and Correctional Settings. Journal of Offender Rehabilitation, 35(2), 1-17.

CAMP, S., \& GAES, G. (2005). Criminogenic Effects of the Prison Environment on Inmate Behavior: Some Experimentl Evidence. Crime and Delinquency, 51(3), $425-442$

CEDEÑO, A., \& MONGE, A. (2011). Trabajo Social y Administración de Justicia: las transformaciones del contexto penitenciario costarricense y las repercusiones en los procesos de trabajo profesional. Revista costarricense de Trabajo Social, 1, 4-11.

COLÓN, A., BURGOS, N., \& GARCÍA, V. (2006). La Violencia en la relación de pareja: Estudio de personas convictas por Ley 54. San Juan: Oficina de Procuradora de las Mujeres.

COMISIÓN DE DERECHOS CIVILES DE PUERTO RICO (CDC). (2009). Análisis del sistema correcional puertorriqueño: Modelos de Rehabilitación. San Juan: CDC.
COMISIÓN DE DERECHOS CIVILES DE PUERTO RICO (CDC). (2011). Informe Anual del Observatorio Correccional. San Juan: CDC.

COYLE, A. (2002). International Centre for Prison Studies. Recuperado de La administración penitenciaria en el contexto de los derechos humanos. Manual para el personal penitenciario: http://www.prisonstudies.org/ sites/prisonstudies.org/files/resources/downloads

CRUZ, E., FERNÁNDEZ, E., GONZÁlEZ, J., \& ROMÁN, F. (1990). Reflexiones en torno a la ideología y vivencias masculinas. San Juan: CISS.

CUllen, F. (2005). The Twelve People who Based Rehabilitation: How the Science of Criminology made a Difference. Criminology, 43(11), 1-42.

DAMMERT, L. (2006). EL sistema penitenciario en Chile: Desafios para el nuevo modelo público-privado. San Juan: Ponencia presentada en la Reunión de la Asociación de Estudios Latinoamericanos (LASA).

DIETZ, T. (1998). An Examination of Violence and Gender Role Portreyals in Video Games: Implications for Gender Socialization and Aggressive Behavior. Sex Roles, 38(5), 425-442.

EISNER, E. (1990). The Meaning of Alternative Paradigms for Practice. Newberry: Sage Publication.

FLOOD, M. (1997). Domestic Violence, Boys, Men \& Masculinity. Disponible en Línea. Recuperado de http:// www.xyonline.net/DVtalk.shtml. 4 sep. 2003.

FOCAULT, M. (2009). Vigilar y Castigar. Nacimiento en la Prisión (2a ed.). México D.F: Siglo XXI.

FORASTELLI, F. (2007). Regulaciones culturales y violencia. Reciente debates en el movimiento de mujeres y queer en América Latina. Cátedra UNESCO de la Filosofía para la Paz. España: Universitat Jaume l de Castellón.

FOUCAULT, M. (2010). Las palabras y las cosas: una arqueología de las ciencias sociales (2a. texto revisado ed.). México: Siglo XXI.

GAIAK, B. (2002). Privación de Libertad y derechos fundamentales. Disponible en línea. Obtenido de http:// euslonews.com/05.5zbklgaia51503es.html.

GARCÍA, V. (1982). Estudo da Reincidente. São Paulo: Tesis doctoral no publicada de la Universidad de São Paulo.

GARCÍA, V. (1999). Tratamiento penitenciario. En busca de nuevos paradigmas. Revista del Colegio de Abogados de Puerto Rico, 60(1), 113-130.

GARCÍA, V. (2012a). Violencia estructural y Trabajo Social: Nuevos paradigmas de acción e intervención. Revista costarricense de Trabajo Social, Edición Especial, 19-31.

GARCÍA, V. (2012b). Informe de visita a institución correcional Guayama 1000. Comisión de Derechos Civiles de Puerto Rico. San Juan: Documento Inédito. 
GARCÍA, V., \& CINTRÓN, I. (2012). SUCH IS LIFE. IN S. RODRÍGUEZ, \& S. NEGRÓN (Eds.). San Juan: Terranova.

GARCÍA, V., RAMÍREZ, R., \& SOLANO, L. (2007). Los Hombres no Lloran. San Juan: Huracán.

GIL, D. (1999). Understanding and Overcoming SocialStructural Violence. Contemporary Justice Review, 2(1), 23-35.

HANLEY, D. (2006). Appropiate Services: Examining the Case Classification Principle. Journal of Offender Rehabilitations, 42(4), 1-22.

HARRIS, H. (2017). The Prisoner Dilema. Foreing Affairs, 1(1), 118-129.

HOOD, R., \& SPARKS, R. (1970). Problemas clave en Criminología. Madrid: Edición Guadarrama.

IMMAGERION, R., \& GRENE, J. (2008). Alternatives to Prison. Retrieved from http:www.drugpdiy.org/ library/041708diversion.cfmm

KAUFMAN, M. (2003). The AIM Framework. Addressing and Involving Men and Boys to Promote Gender Equality and End Discrimation and Violence. UNICEF. Recuperado de http://www.michaelkaufman.com/articles/pdf/the-aim-framework.pdf

KESTER, W. (2007). Trabajo Social Criminológico: aportes desde la criminología crítica. Facultad de Ciencias Sociales, Escuela de Trabajo Social. San José: Universidad de Costa Rica. Recuperado de http://www.ts.ucr.ac.cr/ binarios/tfglic/tfg-1-2007-09.pdf

KIMMEL, M. (Ed.). (2000). The Gendered Society. New York: Oxford University Press.

KNIGHT, K., GARMEN, B., D, S., M, D., \& FLYNN, P. (2006). An Assesment for Criminal Thinking. Crime $\mathcal{E}$ Delinquency, 52(1), 159-177.

KRIENERT, J. (2003). Masculinity and Crime. A Quantitative Exploration of Messerschmidts Hypothesis. Recuperado de Illinois State University : http://www.sociology.org/ content/vol7.2/01_krienert.html.

KUHN, T. (2004). La estructura de las revoluciones científicas (8a ed.). México: Fondo de Cultura Económica.

LANCASTER, R. (1992). Life is Hard: Machismo, Danger, and the Intimacy of Power in Nicaragua. Los Ángeles: Univesity of California Press.

LEVIT, N. (2001). Male Prison: Privacy Suffering and the Legal Construction of Masculinity. In Q. Sabo, T. Kupers, \& W. London, Prison Masculinities (pp. 93-112). Philadelphia: Temple University Press.

MADRIGAL, L. (2009). Desacralizar la Violencia. Recuperado de www.unavidadiferente.org/p\&f/ponencialarrymadrigal/191309

MARTÍNEZ, S. (2015). ¿Cuestión Social o Cuestión de Orden Social? Incomodidades conceptuales, rupturas y nuevas cartografías. XV Conferencia Conmemorativa
Dorothy D. Bourne. San Juan: Escuela Graduada de Trabajo Social Beatriz Lassalle de la Universidad de Puerto Rico.

MARTINUZZI, M. (2013). Continuidades y rupturas discursivas sobre la violencia de género en la Argentina. Revista Tram [p] as de la comunicación y la cultura, 47(1), 97-107.

MESSERSCHMIDT, J. (2001). Masculinity, Crime and Punishment. In Q. Sabo, T. Kupers, \& W. London, Prison Masculinities (pp. 67-73). Philadelphia: Temple University Press.

MOON, M., SUNDT, J., CULliN, F., \& WRIGHT, J. (2000). To Child Saving Dead? Public Support for Juvenile Rehabilitation. Crime \& Delinquency, 46(1), 38-60.

NELSON, M., V, S., CAMPBELL, N., \& DE-MELLO, J. (2006). The effects of moderate physical activity on offenders in rehabilitative program. The Journal of Correctional Education, 57(4), 276-285.

NORRIS, I., LARSEN, J., \& STASTNY, B. (2010). Social Perceptions of Torture: Genuine Disagreement, Subtle Malleability, and In-Group Bias. Journal of Peace Psychology, 16(3), 275-294.

ORGANIZACIÓN DE LAS NACIONES UNIDAS (ONU). (2005). Los derechos humanos y las prisiones. Manual de bolsillo de normas internacionales de derechos humanos para funcionarios de instituciones penitenciarias (Vol. Serie de capacitación profesional número 11). New York: ONU.

ORTMARN, R. (2000). The Effectiveness of Social Therapy in Prisons - A Randomized Experiment. Crime $\&$ Delinquency, 46(2), 214-232.

PÉREZ, A., LEIFMAN, S., \& ESTRADA, A. (2003). Reversing the Criminalization of Mental Illness. Crime $E$ Delinquency, 49(1), 62-78.

PHILlIPS, J. (2001). Cultural Constitution of Manhood in Prison. Psychology of Men E Masculinity, 2(1), 13-23.

QUIROZ, F., \& PINEDA, J. (2009). Subjetividad, identidad y violencia: masculinidades encrucijadas. Universitas humanistica , 67(1), 81-103.

RAMÍREZ, R., GARCÍA, V., VÉLEZ, M., \& CUNNINGHAN, I. (2002). Masculine Identity and Sexuality. In R. Ramírez, V. García, \& I. Cunninghan (Eds.), Caribbean Masculinities: Working Papers (pp. 83103). San Juan: University of Puerto Rico.

RIVERA, E. (2009, abril 15). La violencia simbólica. El Nuevo Día, p. 56

RODRÍGUEZ, A. (2011). El Trabajo Social en la relación jurídico-penitenciaria. Documentos de Trabajo Social: Revista de trabajo y acción social, 49(1), 155-172.

RODRÍGUEZ, A. (2013). La Criminalización del Entretenimiento Violento: Los Videojuegos como espacio de Transgresión de lo Cotidiano. In S. Serrano (Ed.), 
Registros Crimonológicos Contemporáneos (pp. 189-202). San Juan: SITUM.

SABO, Q., KUPERS, T., \& LONDON, W. (2001). Gender and Politics of Inmates. In Q. Sabo, T. Kupers, \& W. London (Eds.), Prison Masculinities (pp. 3-18). Philadelphia: Temple University Press.

SCELFO, J. (2007). Men \& Depression: Facing Darkness. Newsweek, 21(1), 43-49.

SCHAUFELI, W., \& PEETERS, M. (2000). Job Stress and Burnout Among Correctional Officers: a literature review. International Journal of Stress Management, 7(1), 19-48.

SHIFTER, J. (1998). Amor de Machos. San José: ILPES.

SIEGEL, L. (1992). Criminology. New York: West Publishing Company.

SIM, J. (1995). Tougher than The Rest? Men in Prison. In T. Newborn, \& E. Stanko (Eds.), Just Boys Doing Bussiness (pp. 100-118). New York: Routledge.

SOUNDERS, M. (2006). The Evolution of Correctional Programs. Corrections Today, 68(7), 1-3.

SPIROPOULOS, G., SPRUANCE, L., VAN-VOOCHIS, P., \& SHMITT, M. (2005). Pathfinder and Problem Solving. Comparative Effects of Two Cognitive-Behavioral Programs Among Men and Women Offenders in Community and Prison. Jounal of Offender Rehabilitation, 42(2), 69-94.

STEELE, T., \& WILICOX, N. (2003). A View From the Inside: The Role of Re description Detinance and Masculinity on Inmate Support for the Death Penalty. Crime E Delinquency, 49(2), 285-312.

TAYLOR, H. (2007). Prisoners of the System. Modern Health Care, 37(8), 25-27.

TOCH, H. (1998). Hypermasculinity and Prison Violence. In L. Bowker (Ed.), Masculinities and Violence (pp. 168-178). Thousand Oaks, CA: Sage.

TORRES, L. (2014). Alternativas a la Prisión: Hacia una Justicia restauradora. San Juan: En fase de publicación.

TRAVIS, J., \& PETERSILIA, J. (2007). Reentry Reconsidered. A Newbook at an Old Question. Crime $\mathcal{E}$ Delinquency, 47(3), 291-313.

UMBREIT, M. (1996). Victim meets offender. New York: Willow Three Press.

VON-GAUDECKER, H., VAN-SOEST, A., \& WENGSTROM, E. (2011). Heterogeneity in Risky Choice Behavior in a Broad Population. American Economic Review, 101(2), 664-694.

VON-SOEST, D. (1997). The Global Crisis of Violence. Washington: NASW Press.

WILliAMSON, B. (2005). Políticas y Programas de Rehabilitacióny Reinserción en Cárceles. Recuperado de RevistaPaz Ciudadana: http://www.pazciudadana.cl/wp-content/
uploads/2013/07/2005-09-07_Pol\%C3\%83\%C2\%ADticasy-programas-derehabilitaci\%C3\% 83\% C2\%B3n-yreinserci\%C3\%83\%C2\%B3n.pdf

WILlliAMS, M. S., \& DEANE, F. (2007). Attitudes of Male Prisoners Towards Seeking Professional Psychological Help. Journal of Offender Rehabilitation, 34(2), 49-61. 